emigrantes brasileiros radicados nos EUA, por meio de seus veículos de comunicação intragrupal, engendram maneiras peculiares de ser, ver e sentir o mundo. Tais cosmovisões caracterizadas por subjetividades em trânsito podem constituir aquilo que Boaventura de Sousa Santos define como ecologia de saberes, desde que interpretadas à luz de metodologias e teorias contra-hegemônicas de análise.

Ano/Edição Ano XXVI, no 73, jul-dez/2013. São Paulo

\begin{tabular}{ll}
\hline Título & $\begin{array}{l}\text { Imigração haitiana e a relação com comunicação, consumo e } \\
\text { trabalho }\end{array}$ \\
\hline Autor/es & Cristóvão Domingues de Almeida \\
Resumo & O artigo tem como objetivo debater comunicação, consumo, \\
trabalho enquanto processo de mediação dos imigrantes \\
haitianos em São Paulo e compreender de que forma os \\
haitianos se articulam para superar as desvalorizações, a \\
precarização e a informalidade, uma vez que muitos deles têm \\
qualificações, mas desenvolvem atividades laborais aquém \\
das suas formações profissionais. Com base em observação \\
e entrevista em profundidade com os haitianos é possível \\
constatar que eles mantêm as expectativas de acesso ao \\
mundo do trabalho e o desejo de melhorar as condições de \\
vida, sendo que para isso mobilizam-se em redes migratórias. \\
Evidenciamos que os usos e as articulações, através da \\
comunicação face a face e das plataformas digitais, ajudam \\
a superar as situações de desvalorização da força vital do \\
trabalho, garantindo a permanência, fortalecendo as lutas e \\
melhorando as condições de vida.
\end{tabular}

\title{
INDÍGENAS
}

Título Autor/es Resumo

\section{Os pankararé do brejo do burgo na cidade de São Paulo}

\section{Lidia Izabel da Luz}

Este artigo trata da migração temporária de índios Pankararé de Brejo do Burgo para São Paulo, a partir de 1955. O Brejo do Burgo fica na Bahia, na região do Sertão de Paulo Afonso. Considerando a violência dos conflitos agrários que atinge os Pankararé, o artigo busca compreender como São Paulo significa para esta etnia indígena, um entre outros espaços que tiveram 
de ocupar, ao longo de sua história, para continuar mantendo seus meios de vida no local de origem, reproduzidos segundo sua maneira própria e diferenciada de ser, de conceber e ordenar o mundo. Nessa medida, migrar é também uma forma de resistir; de continuar vivendo como desejam e como são.

Ano/Edição Ano I, no 1, maio-ago/1988. São Paulo-SP

Título

Autor/es

Resumo Ano/Edição

Título Autor/es Resumo Ano/Edição

Título

Autor/es Resumo
Governo mente ao anunciar demarcação da área Yanomani (Denúncia)

\section{CIMI - Conselho Indigenista Missionário}

(Denúncia)

Ano I, no3, jan-abril/1989

\section{Nas terras Waimiri-Atroari - projetos de morte}

\section{Egydio Schwade}

Como todos os grandes projetos executados nos últimos 20 anos pelo governo e empresários na Amazônia, Balbina foi concebida nos gabinetes refrigerados de Brasília e Manaus. Em 1972, pelo menos oito aldeias Waimiri-Atroari ou Kinã localizavam-se na região do lago de Balbina, todas elas interligadas por varadouros que, por sua vez, como uma teia de aranha ligavam também as aldeias Karib da região Norte do país e países vizinhos. A partir de 1973, os Waimiri-Atroari já começaram a sentir os efeitos do projeto Hidrelétrico de Balbina. A FUNAl e o 60 Batalhão de Engenharia e Construção (BEC) começaram a reprimir os índios na margem leste da BR-174, impedindo-lhes o livre trânsito naquela parte de seu território tradicional. Começou aí a reação dos WaimiriAtroari, que culminou com o massacre do sertanista da Funai, Gilberto Pinto e demais funcionários do Posto Abonari II, à exceção de um só. Este artigo apresenta os meandros desse violento processo de violação de direitos étnicos e territoriais dos Waimiri-Atroari engendrado pelo Estado brasileiro e empresas em nome do progresso.

Ano II, no 6, jan-abril/1990. São Paulo

O preconceito tecnológico e o conhecimento indígena da natureza

\section{Eduardo Carrara}

Os índios ainda hoje. passados quinhentos anos do 
descobrimento da América (1492), são alvo de muitos preconceitos. O mais forte deles é o preconceito tecnológico do Ocidente, o qual caracteriza os índios das Américas como "sociedades primitivas". Segundo interpretações de missionários, viajantes e precursores do estudo antropológico, tais eram vistas como possuidoras de uma tecnologia incipiente (domínio rudimentar sobre a natureza). de hábitos e costumes de povos não civilizados, isto é. "selvagens" e bárbaros". Tratarei sucintamente da origem cientifica deste preconceito específico e de como se deve lançar um novo olhar sobre as culturas indígenas, Uma vez que a "cultura material" indígena também é elaborada através do pensamento e conhecimento que estes povos possuem da natureza, aqueles devem ser bases de sustentação de tecnologias avançadas que lidam hoje com o meio ambiente e seu desenvolvimento.

Ano/Edição Ano VII, no18, jan-abril/1994

\section{Título \\ Autor/es \\ Resumo \\ Ano/Edição}

\section{Índios e territórios}

\section{Dirceu Cutti}

Editorial

Ano IX, no 24, jan-abril/1996. São Paulo

\section{Título}

Autor/es

Resumo
Viagens de ida, de volta e outras viagens: os movimentos migratórios e as sociedades indígenas.

\section{João Pacheco de Oliveira}

A representação ocidental sobre 0 índio como um "primitivo" assegura a ordenação da diversidade humana e simultaneamente prescreve o destino das sociedades indígenas. Desintegração, assimilação, anomia c deslocamento populacional são as consequências previsíveis deste processo, onde o progresso apresenta-se como a resultante de uma tendência inelutável $\mathrm{cm}$ abandonar a primitividade e adotar os modos de comportamento dados como mais "civilizados". Uma tentativa muito limitada (embora libertária e bem intencionada) de modificar esta forma de pensar sobre as sociedades indígenas é trocar os sinais valorativos implícitos na história oficial. Para isso é possível beber em muitas fontes, entre elas a tradição indianista na literatura, o positivismo na versão rondoniana, como também recuperar uma vertente romântica do próprio pensamento social. Nessa via a "descoberta' 'passou a ser descrita como a ' 'conquista' a epopeia da formação nacional foi substituída pela tragédia 
da destruição da população autóctone. Ainda que tais formulações tivessem uma importante função politicopedagógica ao contrapor-se aos discursos dominantes, muitas vezes tais mudanças não corresponderam a um avanço real no conhecimento daquele processo histórico, não aportando novos materiais etnográficos c documentais que tivessem uma efetiva capacidade explicativa, É importante precaver-se para que no futuro tais postulações não percam a condição de chaves interpretativas, sendo automatizados como atos simbólicos de mera reiteração identitária, que vêm a constituirse $\mathrm{cm}$ uma frágil e insuficiente base para o estabelecimento de estratégias políticas eficazes para as sociedades indígenas.

Ano/Edição Ano IX, no 24, jan-abril/1996. São Paulo

Título

Autor/es

Resumo
De como "chegar a ser gente": etnicidade e hierarquia entre migrantes indígenas em Manaus

\section{Jorge O. Romano}

Os efeitos do crescente processo de urbanização, que se tem manifestado nos últimos cinquenta anos com o crescimento da migração das populações rurais e das pequenas cidades para os polos urbanos regionais de desenvolvimento industrial e comercial, também expressam-se entre os povos indígenas que mantêm contatos antigos com a sociedade nacional. A cidade de Manaus, no coração da Amazónia, é um desses polos, apresentando durante muito tempo um dos maiores ritmos de crescimento demográfico do país, concentrando um alto fluxo de migração extra e intra-regional, incluindo populações indígenas originárias de várias nações ou grupos como, por exemplo, Tukano, Apurina, Mura, Munduruku e Sateré-Mawé. Os problemas que se manifestam em Manaus, em torno dos conflitos que sofrem os migrantes indígenas, remetem-nos aos fenómenos de 'etnicidade" em áreas urbanas $^{2}$. A etnicidade é entendida como um conceito que cobre uma gama de fenômenos relativos a comportamentos e crenças de agentes condicionados pela situação de membros de povos ou etnias inseridas em sociedades receptoras. Na dimensão da estrutura social consideram-se as etnias enquanto relações que permitem delinear grupos de identidade minoritários nas diversas situações de contato interétnico onde o conflito - latente ou manifesto - é a qualidade distintiva. Na dimensão da identidade, a etnicidade remete ao plano das representações e das manifestações ideológicas. A identidade étnica é essencialmente contrastiva. Funciona como uma espécie de "condensador ideológico" 
que guarda a energia das contradições, as quais são produto tanto da 'linha étnica' ', como também, frequentemente, da "linha de classe". As relações conflitivas de dominaçãosujeição, que se estabelecem a partir dessas contradições, são as que, em geral, conformam e caracterizam as identidades étnicas, estigmatizando a uma delas - como acontece com a identidade de "índio" - e dignificando a outra, em nosso caso, a de "civilizado"

Ano/Edição Ano IX, no 24, jan-abril/1996

Título

Os Kaingang do Paraná e seus deslocamentos cíclicos para o Mato Grosso do Sul

Autor/es

Kimiye Tommasino

Resumo

Este artigo refere-se a uma sociedade meridional e à experiência recente de alguns de seus membros como trabalhadores temporários no município de 13rasilândiaMS. Os Kaingáng dos Postos Indígenas Apucarana (município de Londrina), Barão de Antonina e São .Jerônimo (município de São .Jerônimo da Sena), localizados na região norte do Estado do Paraná, começaram a se deslocar para a Fazenda da Destilaria Brasilândia SIA-I) IF.13RASA há cerca de cinco anos, onde vão cortar cana-de-açúcar, Permanecem por períodos de dias e repetem essas viagens três a quatro vezes ao ano. Os Kaingáng pertencem ao tronco linguístico Jê e vivem hoje nas reservas Indígenas dos Estados de São Paulo, Paraná, Santa Catarina e Rio Grande do Sul. No total são cerca de 20 mil pessoas, No Paraná vivem pouco mais de oito mil, distribuídos em I I postos indígenas. Nossa pesquisa refere-se aos Kaingáng de três postos que se localizam na região norte do Estado do Paraná: Postos Indígenas Apucarana (município de Londrina), 13arão de Antonina e São Jerónimo (município de São Jerónimo da Serra).

Ano/Edição Ano IX, no 24, jan-abril/1996

\section{Título}

Autor/es

Resumo

\section{Por falar em paraíso terrestre}

\section{Alcida Rita Ramos}

Ao fim de sua quarta viagem ao Novo Mundo e até a hora da morte, Cristóvão Colombo estava certo de haver chegado à entrada do Paraíso Terrestre. Convenceu-se disso quando viu a foz de um grande rio, majestoso. amazónico. Era o Orinoco. A impressão foi tão forte que só o apelo ao divino pôde satisfazer os sentidos do comandante do Mar Oceano. Tamanha grandiosidade só poderia ser coisa de Paraíso, aquele portento líquido tinha que ser um dos quatro rios do Éden, se 
não chega a corresponder às fantasias edénicas de Colombo, o rio Orinoco merece seu lugar na história por várias razões dentre os quais, o privilégio de abrigar um dos povos indígenas mais conhecidos da atualidade. No alto de suas cabeceiras, metade dos Yanomami se espalham por uma infinidade de igarapés que só não são também brasileiros porque a barreira do Maciço das Guianas impede-os de correr para o sul. Mas, do lado de cá desse magnífico divisor de águas, fonte de inspiração para fantasias como as de Conan Doyle sobre um mundo perdido, vive a outra metade dos Yanomami. Ao todo são cerca de 20 mil índios, falando quatro línguas distintas, mas intimamente relacionadas, plantando suas roças, explorando os recursos naturais de uma floresta sempre pródiga desde que respeitada em sua essência, passando às novas gerações um estilo cultural que lhes vem garantindo não só um nível de vida satisfatório, como também a notável capacidade de expandir seu território.

Ano/Edição Ano IX, no 24, jan-abril/1996

\begin{tabular}{ll}
\hline Título & Migrações Guarani Mbya \\
Autor/es & Maria Ines Ladeira \\
Resumo & Neste artigo comentaremos as migrações Guarani Mbya a \\
partir de alguns pressupostos contidos nos seus mitos de \\
origem que fundamentam os movimentos atuais². Os Guarani \\
contemporâneos que vivem no Brasil são classificados. a \\
partir da década de por Egon Schaden em 3 grupos - Kaiova \\
(ou Pai Tavyterã, no Paraguai), Nhandeva e Mbya - conforme \\
diferenças dialetais. de costumes e de práticas rituais. Essa \\
divisão fundamenta-se numa definição de diferença apontada \\
e vivida por esses próprios índios, observada na disposição \\
dos espaços que ocupam dentro de um grande território \\
tradicional constituído pela antiga região de Misiones \\
(Argentina e Paraguai). norte do Uruguai e regiões Centro- \\
Oeste, Sul e Sudeste do Brasil. No litoral brasileiro, as aldeias \\
Guarani (Nhandeva e Mbya) estão localizadas entre os estados \\
do Rio Grande do Sul e Espírito Santo. Apesar do constante \\
processo migratório e da miscigenação entre os vários grupos \\
Guarani com experiência ou não nas reduções jesuíticas, os \\
Guarani Mbya mantêm sua unidade cultural e linguística bem \\
determinada que lhes permite reconhecer seus iguais, mesmo \\
vivendo aldeias separadas por grandes distâncias geográficas e \\
envolvidas por distintas sociedades nacionais. \\
Ano IX, no 24, jan-abril/1996
\end{tabular}


Título

Autor/es

Resumo

Ano/Edição

Na terra do aldeamento, na cidade, em todo o litoral: o movimento dos índios Tremembé

\section{Alecsandro Ratts}

Os Tremembé estão entre os grupos indígenas que " reapareceram' no cenário cearense, desde a década de 80 , após mais de cem anos de propaganda "extinção" oficial dos índios no Ceará. Quem fala cm Tremembé geralmente se refere a população indígena que mora em Almofala, local de um aldeamento do século XVIII e que hoje é distrito do município de Itarema, situado a $270 \mathrm{~km}$ de Fortaleza. Os Tremembé de Almofala e aqueles que migraram para Fortaleza estão retornando os vínculos de parentesco no atual contexto da luta pela terra. Esta situação permite discutir território, cidade e visibilidade para os Tremembé.

Título Ano IX, no 24, jan-abril/1996

\section{Autor/es}

Resumo

Os Kaxinawá e os Brabos: territórios e deslocamentos populacionais nas fronteiras do Acre com o Peru

\section{Txai Terri Valle de Aquino; Marcelo Piedrafita Iglesias}

No estado do Acre, nos últimos quinze anos, ao longo de toda a fronteira internacional do Brasil com o Peru, têm ocorrido recorrentes conflitos amados, envolvendo, de um lado, índios Kaxinawá dos rios Jordão e Hurnaitá, Katnpa e Kulina do rio Envira; seringueiros do alto rio Tarauacá e índios Jamináwa e Manchincri do alto rio laco, e, de outro, integrantes de populações indígenas ainda em contato sistemático com o mundo dos seringais, conhecidos regionalmente como os "brabos". Violentos enfrentamentos, que mais frequentemente acontecem nos meses do "verão" (junho a setembro), têm resultado em mortos e feridos de ambos os lados. Neste texto, pretendemos resgatar a secularidade destes conflitos armados entre os "brabos" e os Kaxinawá e seringueiros ao longo da fronteira internacional Brasil-Peru, demonstrando sua continuidade nas diferentes situações históricas que marcaram a vida das populações indígenas inseridas nos seringais nativos dos altos rios do estado do Acre. Será analisado como. nos anos 9(). os saques c ataques dos " "brabos" nas cabeceiras do rio Jordão resultaram na redefinição das formas de ocupação da Terra Indígena, provocando restrições ao uso de importantes recursos naturais $c$ intensos processos migratórios de grupos familiares Kaxinawá para outros quatro seringais situados fora dos limites da terra já regularizada. Destacaremos. ainda, 
como esta expansão do território Kaxinawá está contextual inda em processos económicos c políticos mais amplos, que decorrem da prolongada crise da economia da borracha, da recente criação do Município de Jordão e da atuação de diferentes órgãos do Estado brasileiro, A partir desta situação vivenciada pelos Kaxinawá do rio Jordão, almejamos contribuir para o enriquecimento de estudos que vêm sendo gerados sobre a importância da empresa seringalista como matriz de apropriação territorial c de organização económica e social na faixa de fronteira da região amazónica no presente século, a participação dos índios no traçado e manutenção das fronteiras da nação brasileira, as políticas indigenistas do órgão oficial direcionadas a populações indígenas ditas "isoladas" ou "arredias" c processos de construção de territorialidade, frutos das mobilizações dos índios, em situações marcadas pelas ações do Estado nacional e de outros atores dos âmbitos local c regional.

Ano/Edição Ano IX, no 24, jan-abril/1996

\begin{tabular}{ll}
\hline Título & $\begin{array}{l}\text { Waimiri-atroari: invasão e fragmentação do território } \\
\text { indígena }\end{array}$ \\
\hline Autor/es & José Aldemir de Oliveira \\
Resumo & avanço das relaçães sociais de produção na Amazónia \\
estabelece novas formas e conteúdos espaciais, impondo \\
o novo e destruindo culturas, natureza e modos de vida. \\
Esse processo, se não é específico para a Amazónia, adquire \\
aí maior dimensão, em decorrência da predominância da \\
natureza e de culturas ainda não adaptadas a uma tendência \\
de homogeneização que ocorre com o avanço do capital. A \\
invasão do território dos Waimiri-Atroari é o exemplo de um \\
processo de produção espacial que se dá a partir da destruição \\
quase que completa de seu modo de vida e de sua cultura. \\
Este artigo demonstra, do ponto de vista da espacialidade, \\
a expansão da fronteira na área nordeste do Estado do \\
Amazonas e o processo de ocupação do território dos \\
Waimiri-Atroari, a partir do planejamento e da construção da \\
estrada BR174 (Estrada Manaus-Boa Vista), da construção da \\
Usina Hidrelétrica de Balbina e da implantação do Projeto de \\
Mineração Pitinga do grupo Paranapanema. Esse processo não \\
é linear, mas de certa forma sequencial. Os Waimiri-Atroari \\
ocupavam toda a área que hoje corresponde ao Município de \\
Presidente Figueiredo, situado a 100 quilômetros ao norte de
\end{tabular}




\begin{tabular}{|c|c|}
\hline Ano/Edição & $\begin{array}{l}\text { Manaus, na fronteira sul de Roraima. } \\
\text { Ano IX, no 24, jan-abril/1996. São Paulo }\end{array}$ \\
\hline \multirow{3}{*}{$\begin{array}{l}\text { Título } \\
\text { Autor/es } \\
\text { Resumo }\end{array}$} & $\begin{array}{l}\text { Esbulhos de terras e resistência indígena em Escada-pe no } \\
\text { Século XIX }\end{array}$ \\
\hline & Edson Silva \\
\hline & $\begin{array}{l}\text { No século XIX acontece um grande assalto às terras indígenas, } \\
\text { principalmente a partir de meados do período, quando nas } \\
\text { áreas de povoamento mais antigo ocorre o aumento da } \\
\text { concentração fundiária e, ao mesmo tempo, a população } \\
\text { - formada por libertos, índios, negros e brancos pobres -, } \\
\text { torna-se assalariada, passando a viver na periferia da grande } \\
\text { propriedade (Cunha, 1992, 15). Em Pernambuco, a fertilidade } \\
\text { da Região da Mala Sul com um solo propício ao cultivo da } \\
\text { cana c as proximidades com o Porto do Recife, estimularam } \\
\text { a concentração de engenhos para a fabricação do açúcar. A } \\
\text { lógica da economia agro-exportadora motivou ao longo do } \\
\text { século XIX as invasões pelos senhores de engenho das duas } \\
\text { aldeias indígenas (Barreiros e Escada) existentes na Região. e a } \\
\text { expulsão dos nativos de seus territórios tradicionais. Este texto } \\
\text { objetiva evidenciar o protagonismo indígena cm Pernambuco } \\
\text { no século XIX, no momento cm que o crescimento da produção } \\
\text { açucareira e a modernização da indústria do ramo ocorreram } \\
\text { com grandes custos sociais. com esbulhos de terras dos } \\
\text { indígenas, que tiveram dentre os seus direitos negados, até o } \\
\text { de estarem presentes como ativos participantes cm análises } \\
\text { da história do período. } \\
\text { Ano IX, no } 24 \text {, jan-abril/1996. São Paulo }\end{array}$ \\
\hline \multirow{2}{*}{$\begin{array}{l}\text { Título } \\
\text { Autor/es } \\
\text { Resumo }\end{array}$} & Sociedades indígenas em novo perfil: alguns desafios \\
\hline & $\begin{array}{l}\text { Dominique Tilkin Gallois } \\
\text { O Brasil indígena é hoje composto de mais de } 215 \\
\text { etnias, falando } 170 \text { línguas distintas. Mais de } 3()() .()()() \text { índios, } \\
\text { distribuídos em cerca de } 590 \text { terras descontínuas. Salvo raras } \\
\text { exceções, essas terras não correspondem aos territórios } \\
\text { historicamente ocupados por esses grupos. mas a fragmentos } \\
\text { de espaços percorridos em histórias com mais de } 500 \text { anos, } \\
\text { ou muito menos, levando-se em conta que muitas terras } \\
\text { foram alcançadas e apropriadas recentemente, em processos } \\
\text { de fuga ou de transferência forçada. Desde a promulgação da } \\
\text { Constituição Federal de 1988, já foram registradas cerca de } \\
390 \text { organizações indígenas, que nem sempre correspondem }\end{array}$ \\
\hline
\end{tabular}


ou representam unidades "étnicas", mas facções de um mesmo grupo, ou articulações regionais entre vários grupos. Ao mesmo tempo, modificam-se as condições de acesso da população brasileira aos conhecimentos e informações relativos à chamada "questão indígena". As instituições indigenistas convencionais e as universidades vêm gradativamente deixando de ser o espaço privilegiado para a produção e a difusão de caracterizações atualizadas das sociedades indígenas, enquanto iniciativas nesse sentido são tomadas pelos próprios índios, que obtêm crescente visibilidade em seus movimentos, através de múltiplas formas de articulação com agências governamentais ou não governamentais. E nesse contexto que representantes de algumas sociedades indígenas vêm se apropriando de novos instrumentos disponibilizados pela comunicação globalizada, para divulgar seus projetos políticos e culturais, formatando para o grande público um novo perfil "dos índios", construindo novas imagens que atingem ou agregam um número crescente de comunidades espalhadas em todo o país. Os processos de construção e revisão de identidades decorrentes desta participação em amplas redes de comunicação ainda carecem de sistematização. Por esta razão, qualquer caracterização do atual perfil das sociedades indígenas no Brasil constitui um exercício arriscado, dada a falta de parâmetros para agregar experiências, vozes e situações das mais diversificadas. Para abordar esse quadro complexo, no qual as delimitações étnicas, territoriais ou culturais indígenas apresentam configurações variáveis e em permanente reformulação, apresentarei comentários a respeito de alguns desafios conceituais persistentes no diálogo que as sociedades indígenas se esforçam em ampliar em múltiplas frentes, no Brasil contemporâneo: suas alternativas de representação, suas formas de territorialidade, seus acervos de conhecimentos. São questões que nos obrigam a considerar novos usos e novas instituições relacionadas às identidades. $E$ que nos levam a rever os parâmetros de descrição cultural e, sobretudo, de delimitação das unidades de análise.

Ano/Edição Ano XIII, no 36, jan-abril/2000. São Paulo

Título

Assentamentos indígenas no médio São Francisco: o caso dosTuxá e Pankarú

Autor/es Ely Souza Estrela

Resumo

Dentre os vários

aspectos do cotidiano

que marcam 
indistintamente indígenas e sertanejos/caboclos, relevadas as nuances diferenciais, que aqui não vem ao caso abordar, destaca-se a experiência da migração. Aliás, convém frisar que, desde a chegada dos primeiros colonizadores, o deslocamento forçado tornou-se fenômeno muito conhecido dos indígenas brasileiros. $\mathrm{O}$ foco deste trabalh $\mathrm{O}^{2}$ é acompanhar a trajetória do deslocamento de duas comunidades indígenas - os tuxá e pankararú - que habitam atualmente a região do Médio São Francisco, em períodos não muitos recuados.

Ano/Edição Ano XIV, no39, jan-abril/2001. São Paulo

\begin{tabular}{l|l}
\hline Título & $\begin{array}{l}\text { Fronteiras de tradição cultural Guarani Mbya e a presença do } \\
\text { Jurua (civilizado) nas Reservas Indígenas }\end{array}$ \\
\cline { 2 - 2 } Autor/es & Marília G. Ghizzi Godoy \\
Resumo & Relato \\
Ano/Edição & Ano XVII, no 48, jan-abril/2004 \\
\hline
\end{tabular}

\title{
INDOCUMENTAÇÃO
}

\author{
Título \\ Tá legal? Tudo em ordem? Tudo sob controle? \\ Autor/es \\ Resumo \\ Heinz Dieter Heidemann \\ Ano/Edição \\ Editorial \\ Ano XI, no 30, jan-abril/1998. São Paulo-SP
}

$\begin{array}{ll}\text { Título } & \begin{array}{l}\text { Migraçães internacionais não-documentadas: uma tendência } \\ \text { global crescente }\end{array} \\ \text { Autor/es } & \text { Hugo Graeme } \\ \text { Resumo } & \text { A Globalização é um dos fenômenos mais difundidos do } \\ \text { dos anos noventa e associado a CIC. fluxos financeiros, bens } \\ \text { e informações cruzam fronteiras nacionais em volumes } \\ \text { nunca antes verificados. Globalização e redução massiva dos } \\ \text { custos reais de viagem têm mostrado também um aumento } \\ \text { na escala c complexidade no movimento de pessoas entre } \\ \text { nações. Entretanto, as barreiras oficiais erguidas por Estados } \\ \text { Nações para o influxo de pessoas têm sido mais resistentes } \\ \text { ao processo da globalização do que as barreiras aos fluxos } \\ \text { de informações. movimentos financeiros e mercadorias. } \\ \text { Contudo, as desigualdades, diferenças e complenlentaridades } \\ \text { internacionais que propiciaram os outros fluxos são } \\ \text { impingidos de forma igualmente forte sobre as pessoas. }\end{array}$

